\title{
A prática da dobra: Como o paradigma do origami intermedia a busca pelo conhecimento, inovação e design contemporâneo
}

Folding practice: how the origami paradigm mediates the search for knowledge, innovation and contemporary design

TEIXEIRA, Samanta Aline I

Universidade Estadual Paulista "Júlio de Mesquita Filho" | laranjasat@gmail.com

NAKATA, Milton Koji I Mestre em Arte e Sociedade

Universidade Estadual Paulista "Júlio de Mesquita Filho" I milton@faac.unesp.b

LANDIM, Paula da Cruz I Doutora em Design

Universidade Estadual Paulista "Júlio de Mesquita Filho" I paula@faac.unesp.br

\begin{abstract}
Resumo
A presente pesquisa busca entender o potencial do processo criativo do origami através do método de exploração experimental e através da análise de alguns projetos desenvolvidos em diferentes áreas. São estudadas as trajetórias acadêmicas de Josef Albers e Ron Resch e seus métodos focados na prática da dobra. Dentro do design aplicado, é feito uma análise em cima dos projetos Origami Heart Stent, Ori-Revo e Evolution Door.

Palavras-chave: origami; design; produto; contemporâneo.

\section{Abstract}

This research aims to understand the potential oforigamicreative process through experimental exploration and by analyzing some projects developed in different areas. Josef Albers and Ron Resch's academic careers and methods on the practice of folding are the main focus in this study. Within the applied design, an analysis is conducted on the projects Origami Heart Stent, Ori-Revo and Evolution Door.

Keywords: origami; design; product; contemporary.
\end{abstract}




\title{
1 INTRODUĈ̣̃O
}

O origami é uma arte ancestral do oriente que consiste em dobrar papéis e modelar diversos tipos de figuras representativas da natureza - como os animais -, ou figuras abstratas ? como as formas geométricas. Atualmente, o origami tem apresentado uma série de mudanças significativas em sua maneira de se expressar. De acordo com o físico e origamista Robert J. Lang, um dos principais divulgadores e pesquisadores do assunto, o origami se configura hoje como uma velha e nova arte: sua trajetória histórica possui mais de quinze séculos de existência, porém a concentração de pesquisas inovadoras e aplicações tecnológicas com as dobraduras ocorrem nos últimos trinta anos, ou seja, em apenas $2 \%$ de sua existência (LANG, 2003, p. 3). Confirmam-se nos inúmeros trabalhos de cientistas em todo o globo que o origami tem sido aplicado em muitas áreas distintas. Para citar alguns exemplos, têm-se hoje pesquisas do origami aplicado nas ciências da computação (MITANI, 2009), na educação (ANDREAS, 2011; MENGES, 2015), na medicina (KURIBAYASHI; YOU, 2003, 2009), na robótica (DEMAINE et al., 2010), na astronomia (HYDE et al., 2002), na biologia molecular (ROTHEMUND, 2006; KOMIYAMA et al., 2011), entre outros. A nova exploração da potência multidisciplinar do origami é indicada por Stewart (2007), que afirma ser a busca pela economia de espaço um imperativo no mercado, ao passo que o origami configura-se como um dos paradigmas que traduz efetivamente tal premissa:

\begin{abstract}
Ao longo das últimas duas décadas, um grupo dedicado de matemáticos, engenheiros e cientistas computacionais vem desenvolvendo um novo ramo da matemática para entender a ciência da dobradura de objetos planos. [...] Os resultados têm sido intrigantes e engenhosos, e já possuem aplicações em mapas, embalagens de comida, recipientes de bebidas dobráveis, air-bags de carros e antenas de naves espaciais. (STEWART, 2007, p. 419, tradução nossa).
\end{abstract}

As estruturas interativas em dobras são projetadas de maneira a thes conferir uma mutabilidade de compactação e expansão coexistentes - estado da arte que Lang caracteriza como "pequeno para viagem e grande para o destino". A descoberta do potencial das dobras fez com que o origami se aproximasse ainda mais dos processos biológicos naturais e, com isso, adquirisse dinamismo de adaptação ao seu meio e possibilidades de aplicações em inúmeras áreas tecnológico-científicas:

Estruturas dobradas com base em princípios do origami estão sendo aplicadas em voo espacial, eletrônicos de consumo, saúde e segurança, só para citar apenas algumas das áreas onde origami faz uma aparição inesperada. (LANG, 2009, tradução nossa).

Lang acredita que a aplicação do origami em diversos projetos concretos 
se torne cada vez mais parte da realidade atual e que suas conexões fazem do origami um veículo ideal para unir a matemática, ciências e educação. A aproximação do ramo do origami com a ciência aparenta possuir trajetória recente, contudo Lang evidencia que tal conexão existe a mais tempo do que se imagina:

\begin{abstract}
Os conceitos de origami e ciência parecem estar tão distantes dentro dos campos humanos de atuação quanto você possa imaginar: o primeiro, uma arte, um fazer manual, associado a uma tradição japonesa de centenas de anos atrás; o último, uma rigorosa e racionalista forma do conhecimento. Mas, curiosamente, ambos os campos entrelaçam-se influentemente um no outro, apresentando conexões de diversas maneiras. E, de fato, eles têm feito isso há décadas. (LANG, 2009, tradução nossa).
\end{abstract}

O que mudou não foi a ideia inicial de gestão entre ciência e origami, mas as formas como esses ramos têm se conectado: aumentou-se em grande escala o número de áreas do conhecimento alcançadas ao tratar do origami como uma linguagem científica e projetual. Para entender melhor esse comportamento científico do origami e a sua expansão, utilizamos a plataforma online Web of Science (2016). Tendo sua base de dados aproximadamente 90 milhões de registros que abrangem periódicos, congressos e patentes, a Web of Science demonstra que a pesquisa sobre o origami tem crescido consideravelmente nos últimos 10 anos. Dois gráficos foram gerados a partir da busca em cima do termo origami , um sobre documentos e outro sobre citações:

Figura 1- Gráfico de documentos que possuem o origami como tema principal.

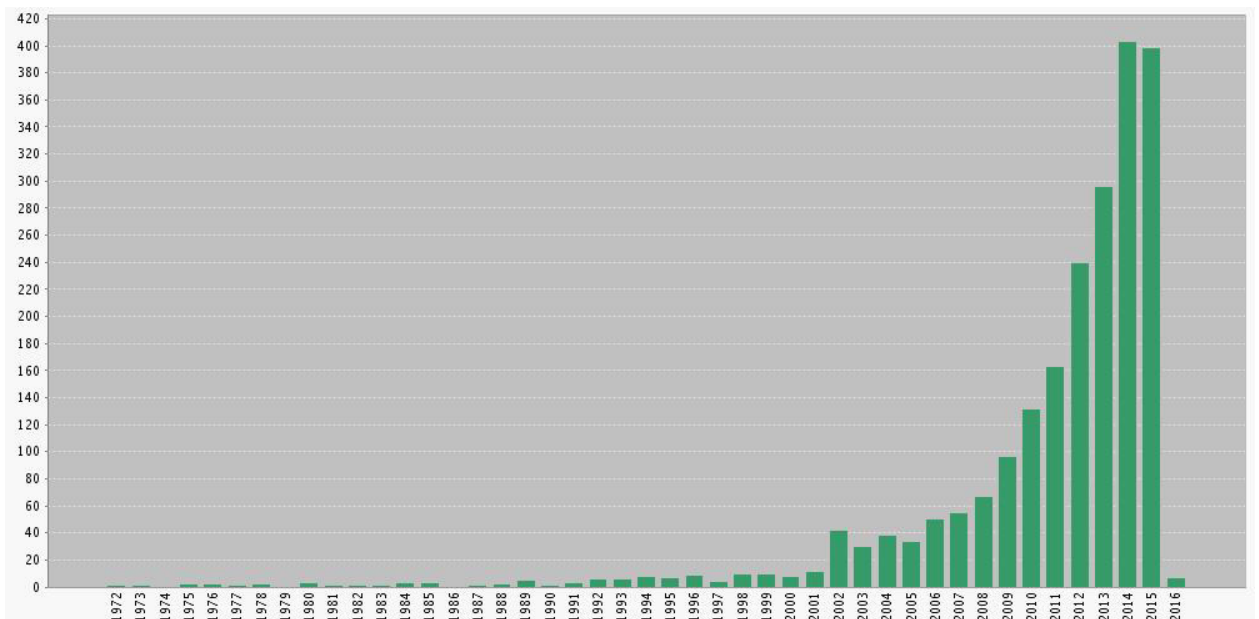

Fonte: Web of Science (2016).

De acordo com o gráfico acima o número de artigos publicados em cima do tópico origami aumentou de 37 em 2005, para 395 em 2015: um aumento de 1067\% (cálculos aproximados). 
Figura 2- Gráfico de citações sobre o tema origami.

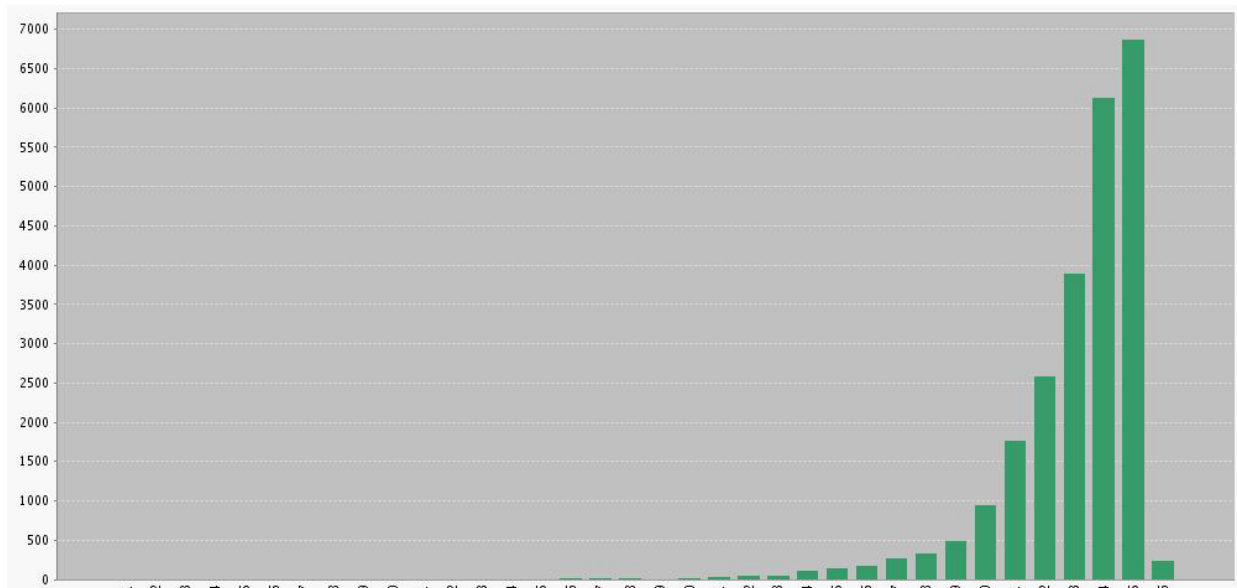

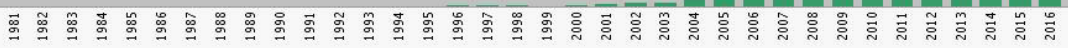

Fonte: Web of Science (2016).

Já o número de citações em diferentes artigos que mencionam o termo origami é ainda maior: por cálculos aproximados, com menos de 200 citações em 2005, o origami foi mencionado por volta de 6900 vezes em 2015: um aumento de $3450 \%$. Esses números são um indício claro de como a natureza do origami contemporâneo tem se configurado atualmente: uma linguagem acessível e versátil em inúmeras situações, inclusive na pesquisa científica.

\section{A BUSCA PELA PRÁTICA DA DOBRA}

O método de busca do conhecimento dos materiais na prática, especialmente os que relacionam as funcionalidades interativas das dobras em papel, está fundamentado na trajetória do professor Josef Albers que, desde os anos 1920, apontou a importância da experimentação de materiais de modo ativo, como evidencia Menges (2015, p. 9, tradução nossa):

O material de experimentação de Josef Albers, conduzido como parte do curso de fundação da Bauhaus, em Dessau, e mais tarde no Black Mountain College, na Carolina do Norte, [...] foi um precursor que gerou a exploração de material em design. 
Figura 3- O professor Josef Albers com seus alunos, em 1946.

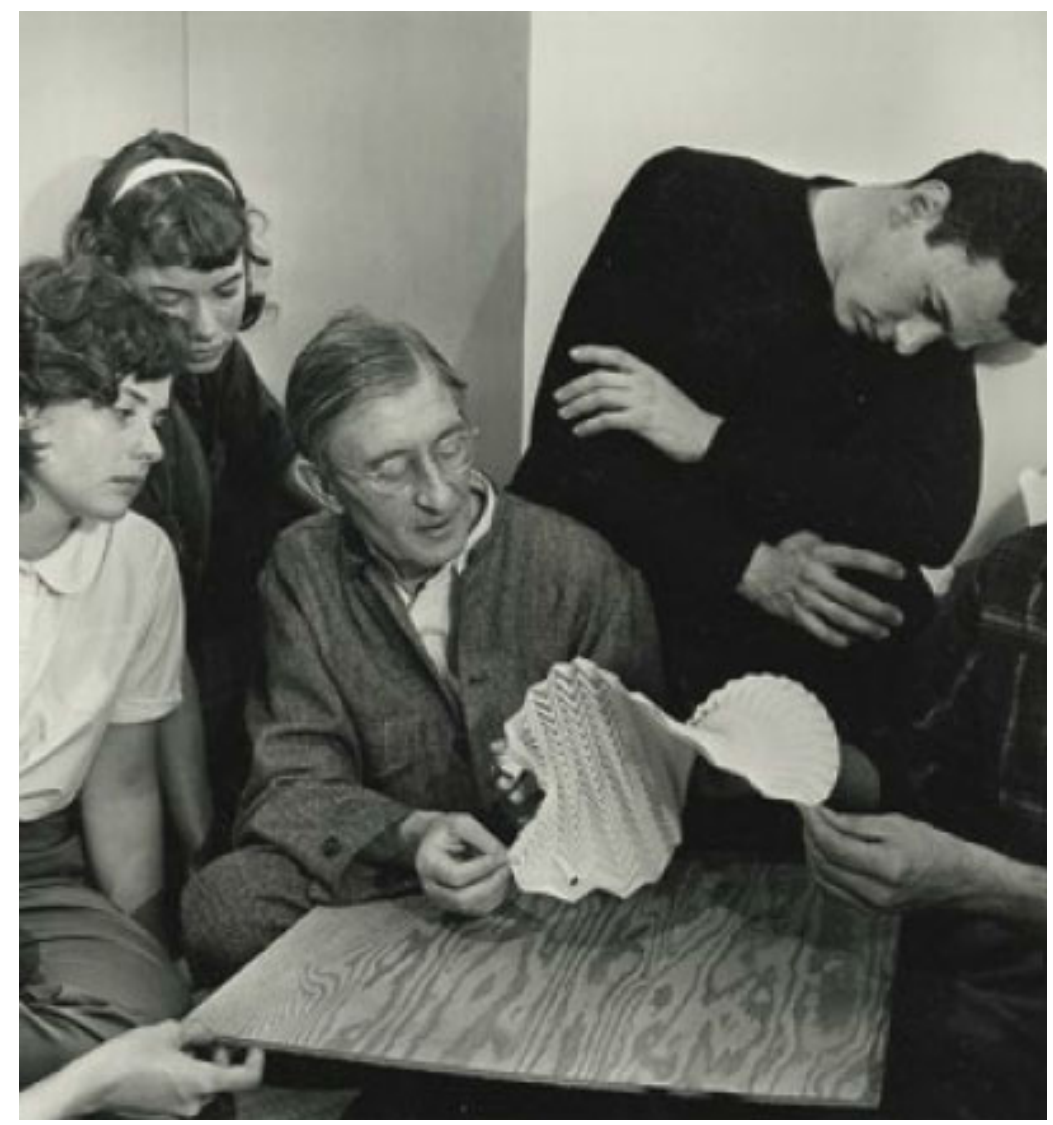

Fonte: Menges (2015).

Menges afirma ainda que o professor Albers "identificou o comportamento próprio do material como uma força motriz em um ilimitado processo criativo que desdobra novas possibilidades de design e inovação no fazer ." (MENGES, 2015, p. 9, tradução nossa). Na figura 03, tem-se Albers com seus alunos estudando padrões híbridos de dobras curvas no papel através de um padrão geométrico contínuo, em 1946, na escola Black Mountain College. De acordo com Erik D. Demaine, Albers acreditava que trabalhar diretamente com os materiais e explorar suas propriedades através da manipulação prática possibilitavam que os designers usufruíssem do máximo de potencial possível desses materiais (DEMAINE et. al., 2015, p. 148). Outro grande precursor histórico dos estudos modernos com o origami foi o professor e artista Ronald D. Resch. Formado em artes na Universidade de lowa e, posteriormente, professor de ciências da computação na Universidade de Utah, Resch desenvolveu uma série de estudos práticos com o origami, fazendo surgir o ramo do Origami Tessellations, nos anos 50 e 60 (FREDERICKSON, 2002, p. 117). 
Figura 4- Um dos padrões em dobras de Ron Resch, em 1959.

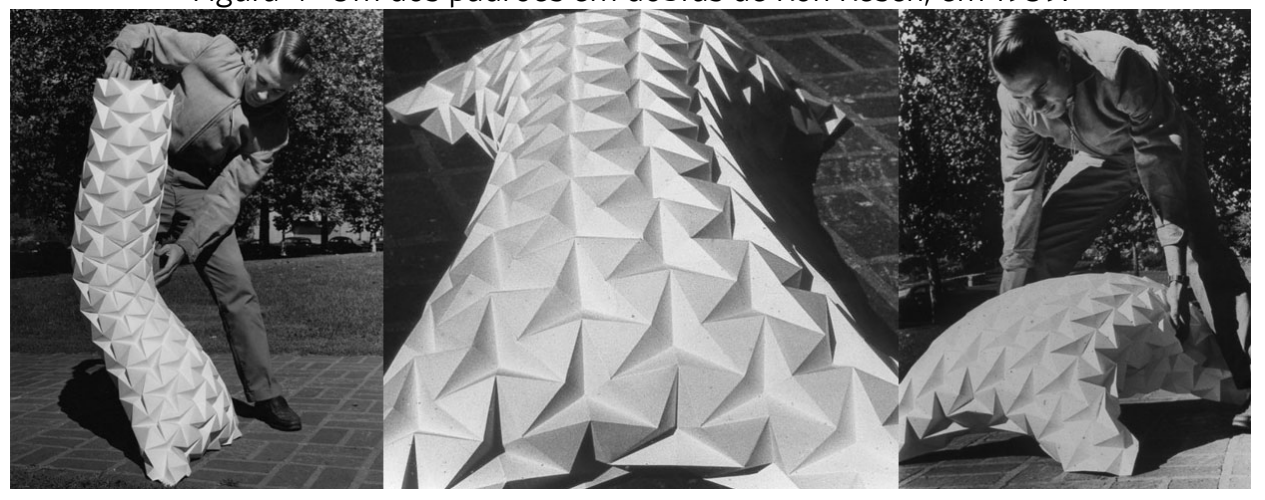

Fonte: Ron Resh Official Website (2016).

Trajetórias históricas como a de Albers e Resch abriram portas para o surgimento de diversos pesquisadores contemporâneos especializados no origami contemporâneo (LANG, 2003, 2009; LANG; IVERSON; YIM, 2011; STEWART, 2007). Na tentativa de traduzir e contextualizar nacionalmente as metodologias proposta por Albers e Resch, oficinas de origami estão sendo realizadas anualmente na Universidade Estadual Paulista desde 2009, buscando a exploração e construção coletiva através da prática manual das dobras.

Figura 5- Oficina de origami oferecida na UNESP, em 2014.

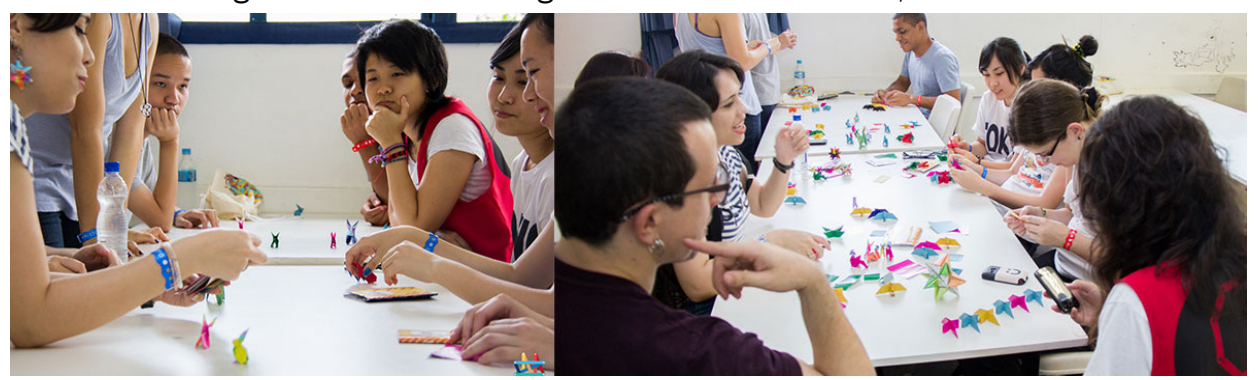

Fonte: Elaboração nossa.

Figura 6- Oficina de origami oferecida na UNESP, em 2015.

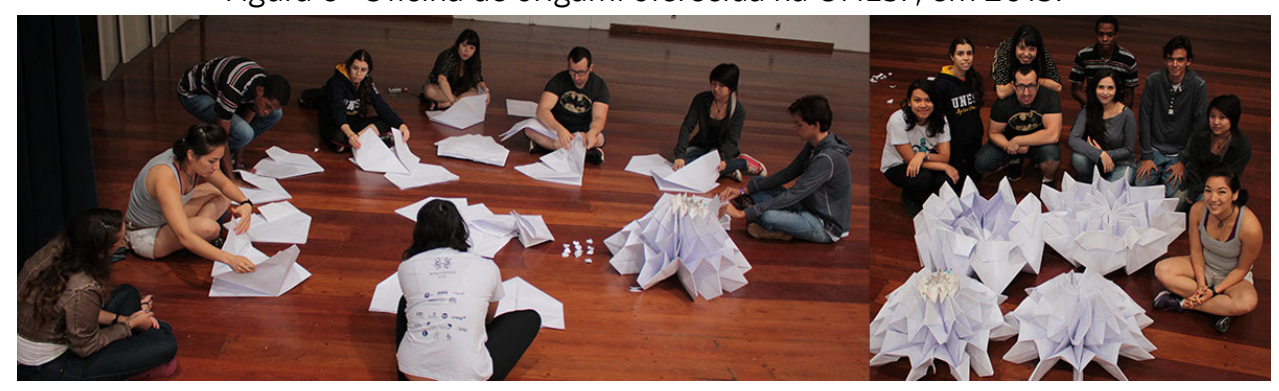

Fonte: Elaboração nossa.

Nas oficinas ministradas, junto à experiência com o papel, os alunos trabalham com a ação em grupo e também com a modulação, ou seja, a construção com módulos. Além da natureza mutável da dobra em si, o filósofo Deleuze, inspirado nos estudos de Gilbert Simondon, indicou na modulação um importante aspecto para questões de adaptação e modificação de uma estrutura: 
Na modulação, nunca há interrupção para desmoldagem, porquanto a circulação do suporte de energia equivale a uma desmoldagem permanente; modulador é um molde temporal contínuo... Moldar é modular de maneira definitiva; modular é moldar de maneira contínua e perpetuamente variável. (DELEUZE, 1991, p. 41-42).

A ação do modular confirma as descrições de Stewart no que diz respeito aos processos tecnológicos que utilizam as dobraduras como ferramentas de raciocínio e aplicação projetual: o origami passa a ser o moderador de diferentes tecnologias e estudos devido ao seu aspecto adaptável, flexível. As dobras possuem a inerência de não se configurarem como um produto final fechado, de forma física estática e perpétua, mas como um módulo que se adapta a diversas situações, possibilitando se encaixar em diferentes realidades e áreas do conhecimento. Dobras que formam o princípio de ação geral de compactação e expansão coexistentes, como o Miura-Ori, do astrofísico Koryo Miura, e o Magic-Ball, do origamista Kade Chan, já foram apropriados de alguma forma pela indústria de produtos (KURIBAYASHI; YOU, 2003, 2009; LANG, 2009), demonstrando o potencial utilitário de alguns modelos de dobradura.

Figura 7- Origami Miura-Ori.

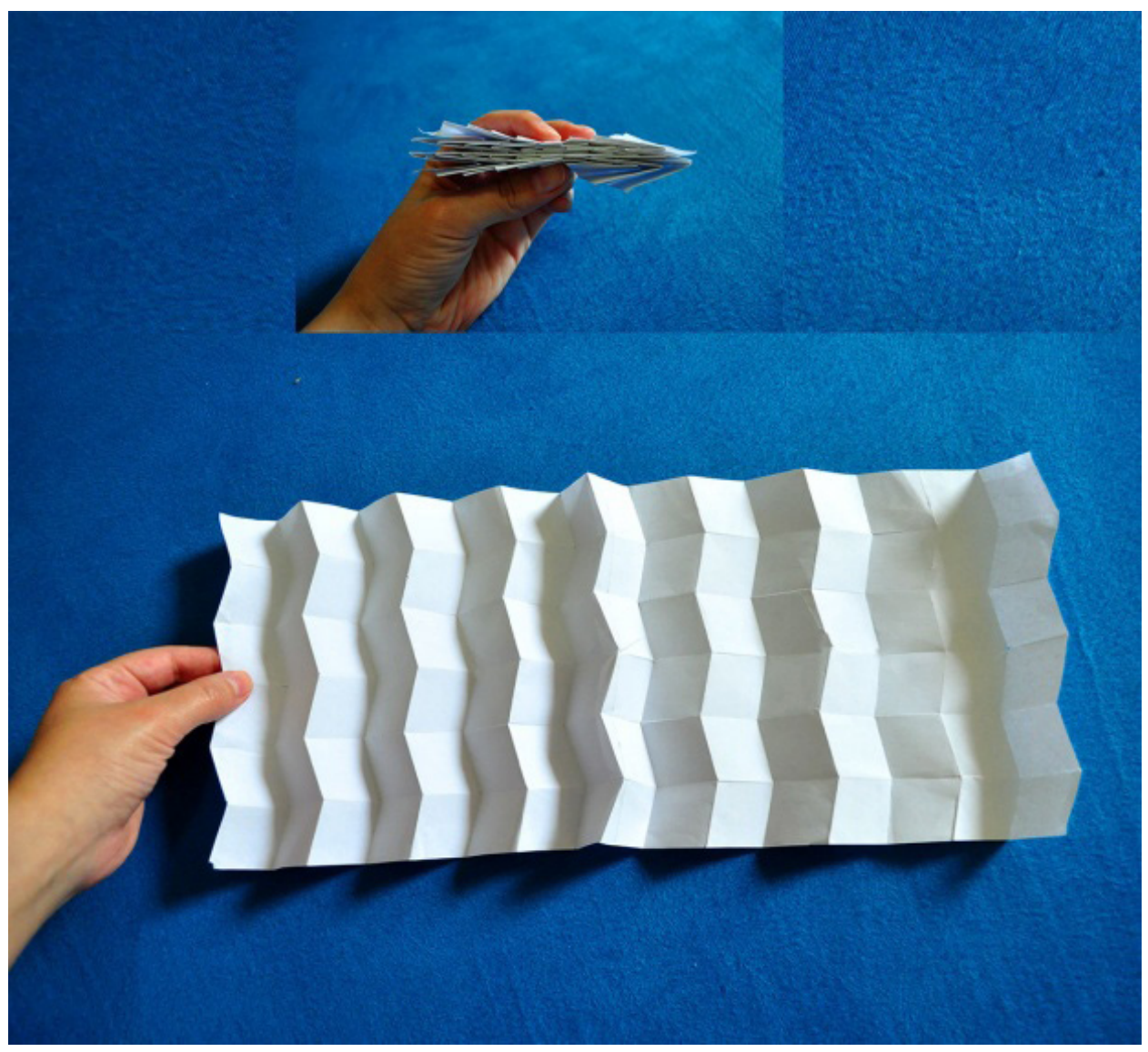

Fonte: Elaboração nossa. 
Figura 8- Origami Magic-Ball.

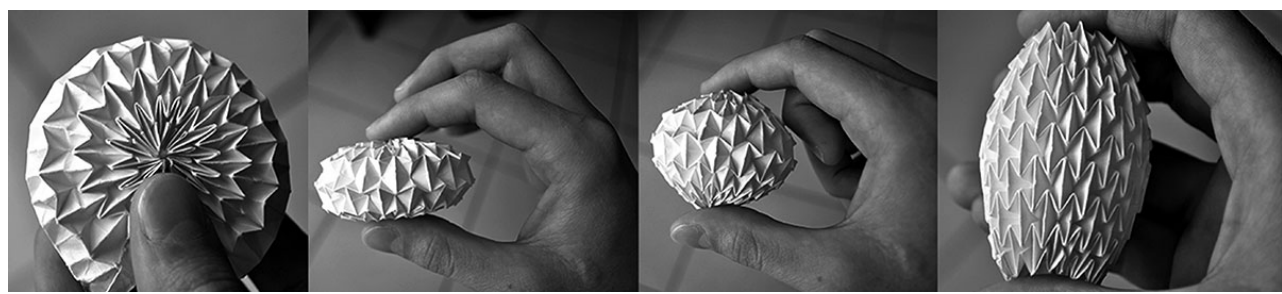

Fonte: Elaboração nossa.

Na figura 7 é possível observar o potencial do padrão de dobras MiuraOri: são dobras simples que se repetem diversas vezes ao longo da superfície, possibilitando que o objeto desdobrado aumente até 10 vezes em relação ao seu tamanho dobrado, quer dizer, trata-se de uma estrutura interativa com grande capacidade de expansão e compactação inerentes. Na figura 8 observase o padrão de dobras Magic-Ball, também conhecido como escamas de peixe : são dobras mais complexas que o Miura-Ori, mas que com a simples manipulação das mãos é possível obter desde um cilindro até um círculo, sem comprometer a estrutura do modelo. Para entender melhor como se dá tal aplicação dos estudos de estruturas dobradas, cita-se a seguir três trabalhos distintos que possuem um raciocínio de projeto claro e objetivo.

\section{ORIGAMI HEART STENT: DA ARTE PARA A MEDICINA}

O Origami Heart Stent é um projeto de origami aplicado à medicina desenvolvido pelo pesquisador Zhong You, membro do Departamento de Ciência da Engenharia da Universidade de Oxford, no Reino Unido, e pela pesquisadora Kaori Kuribayashi, membro do Instituto de Ciência Industrial da Universidade de Tóquio, no Japão. De acordo com Kuribayashi e You (2003), o stent trata-se de um tubo flexível muito comumente usado em alguns processos medicinais cirúrgicos. Capaz de se auto-dobrar, o stent tem a capacidade de consertar determinados problemas biológicos dentro do corpo humano. Sua dinâmica consiste em se compactar ao ser inserido dentro da pessoa (pequeno para a viagem), e expandir-se quando chega ao problema identificado (grande para o destino). 
Figura 9- Protótipo Origami Heart Stent.

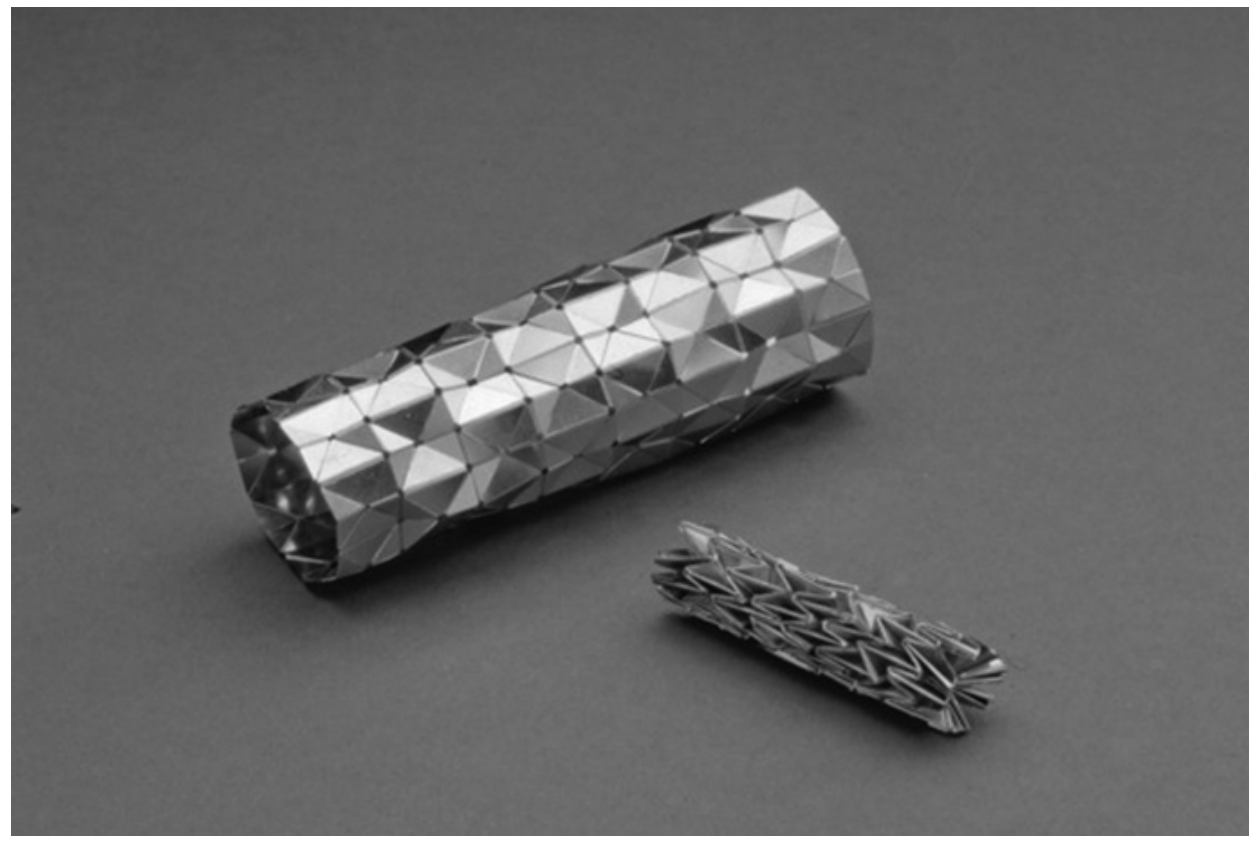

Fonte: Kuribayashi e You (2009).

Na figura acima consta o protótipo do stent em aço inoxidável desenvolvido para o processo cirúrgico da angioplastia. $O$ tamanho original desdobrado possui 2,3 cm., o modelo dobrado possui 1,2 cm., um ganho de espaço de mais ou menos 52,1\%. Como alguns exemplos indicados por Kuribayashi e You, o stent auxilia no tratamento de câncer para esôfago e duto biliar, problemas intestinais e bloqueios cardiovasculares que podem causar infarto. Os antigos projetos de stents são rígidos e limitados em sua forma, são feitos de uma malha metálica com ou sem uma membrana de revestimento externo. O Origami Heart Stent surge como um projeto de produto que busca uma estrutura cinética simples, de fácil adaptação para diferentes aplicações em locais específicos do corpo e que se molde de forma mais livre em diferentes formatos anatômicos.

\section{ORI-REVO: PROCESSO CRIATIVO DIGITAL E FÍSICO}

O origami tradicional surge da manipulação com as mãos. Diversos artistas reconhecidos como Akira Yoshizawa elaboravam diferentes modelos de origami através do contato direto com o papel. Hoje, como tantas outras linguagens, o origami também está sendo digitalizado. Uma das maneiras de origami digitalizado surge com o software Ori-Revo, desenvolvido pelo professor Jun Mitani (2009), da Universidade de Tóquio, no Japão. De livre acesso e sem fins lucrativos, o Ori-Revo funciona através de um gráfico simples com eixo x e y programado em linguagem Java. 
Figura 10- O software Ori-Revo.

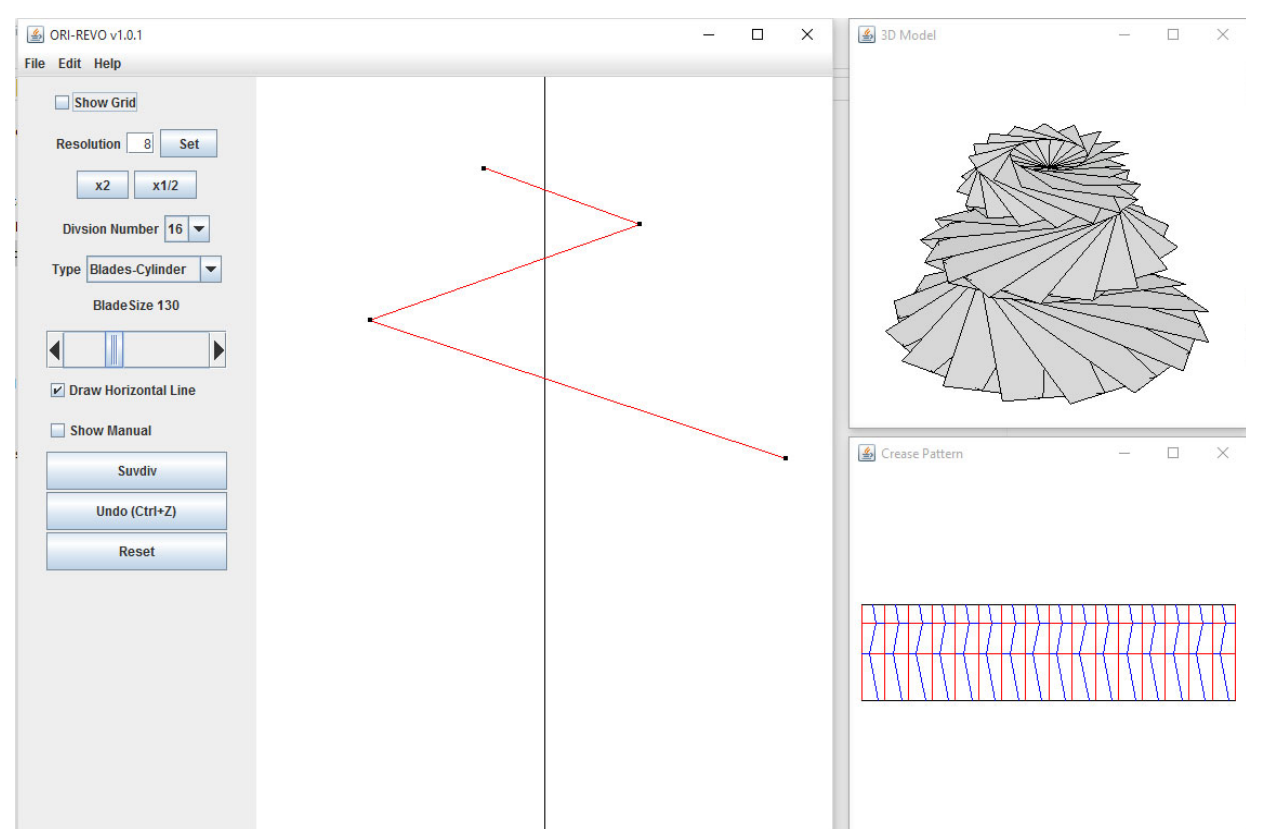

Fonte: Mitani (2009).

Na figura acima consta a interface do software Ori-Revo: no lado esquerdo o usuário pode desenhar livremente com linhas; no lado direito superior o modelo 3D é construído automaticamente através do giro dessas linhas-base em 360, dando-Ihes volume; e por fim, no lado direito inferior está o crease pattern', que possibilita construir o origami fisicamente. A figura 11 ilustra alguns modelos experimentais criados através do programa e dobrados fisicamente:

Figura 11- Modelos de origami criados pelo software Ori-Revo.

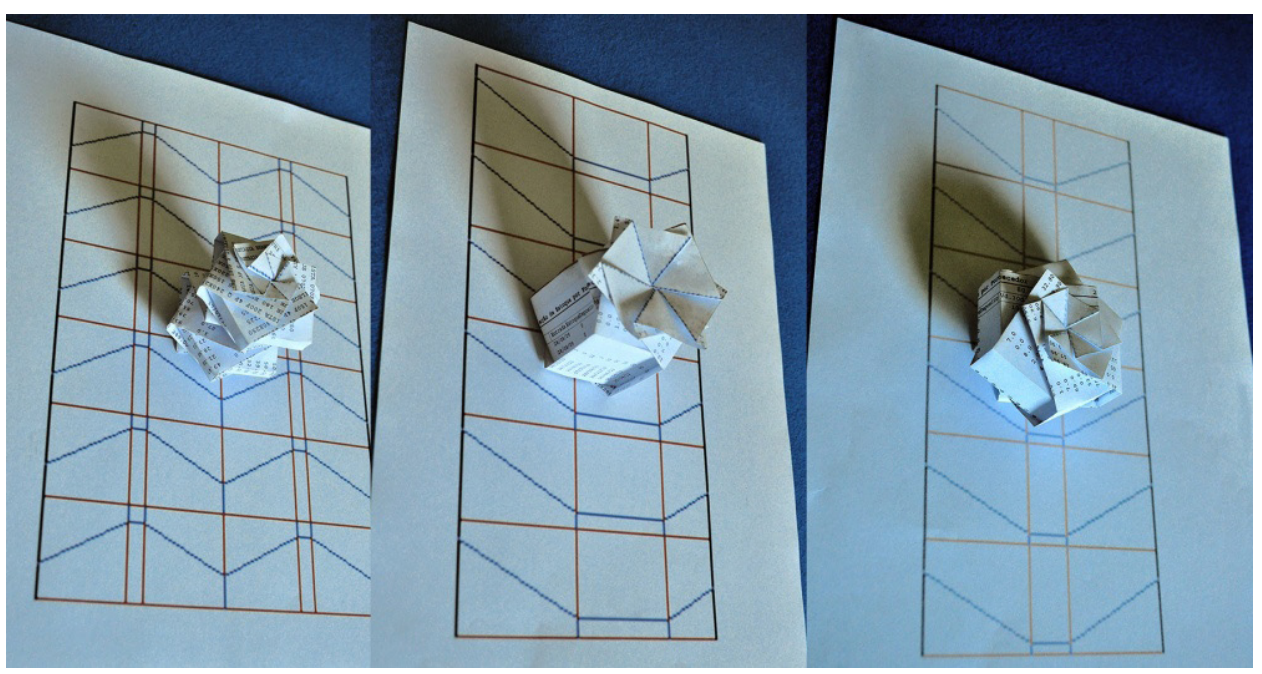

Fonte: Elaboração nossa.

Os modelos dobrados estão em conjunto com seus respectivos mapeamentos em duas dimensões. Com o Ori-Revo, uma nova maneira 
de construir formas em dobras surge através da exploração de linhas pelo computador e sua posterior modelagem física. Transitando entre a mídia digital e manual, o Ori-Revo possibilita diferentes formas de origami e também exclui o elemento do erro: apenas modelos executáveis em dobras são gerados pelo programa. Do simples ao complexo, o programa de Mitani traz novas possibilidades de estruturas dobráveis e, com elas, novas maneiras de se projetar objetos.

Figura 12- Diferentes origamis construídos pelo Ori-revo.
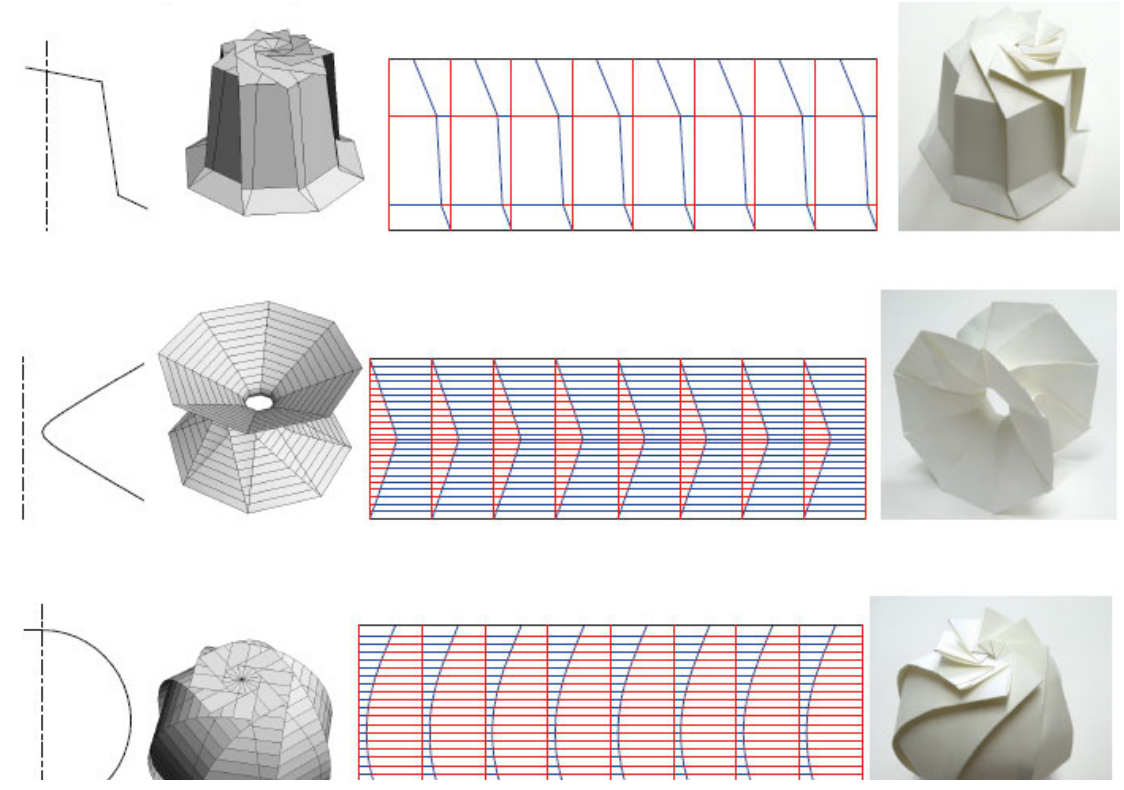

Fonte: Mitani (2009).

De acordo com Mitani, o Ori-Revo possibilita uma liberdade de criação entre duas e três dimensões que pode ser aplicada tanto artística quanto industrialmente (MITANI, 2009, p. 79). Além das possibilidades em formas, o conhecimento de planificação e mapeamento do plano 2D para o 3D somadas às diferentes maneiras de se dobrar um plano fazem do programa Ori-Revo um importante exercício para o design de produtos.

\section{THE EVOLUTION DOOR: O DESIGN DE DOBRAS NOS OBJETOS DO COTIDIANO}

Como um exemplo inusitado de aplicação do raciocínio do origami, citase a porta The Evolution Door, desenvolvida pelo designer vienense Klemens Torggler. Trata-se de um novo projeto de porta, cuja abertura e fechamento baseiam-se em dobras simples de dois quadrados em madeira unidos por um único eixo. Torggler (2015) relata que a porta não possui dobradiças, não têm trilhos ou uma única superfície plana como a maioria das portas comuns.

The Evolution Door possui um mecanismo simples em que ao empurrá-la, como mostrado na figura abaixo, ela se abre e se fecha sozinha. Seu sistema de dobras é simples e minimalista, possui uma contundência e um formato claro, 
fazendo com que sua mudança de espaço e configuração seja uma característica intrínseca ao próprio produto.

Figura 13- A porta The Evolution Door.

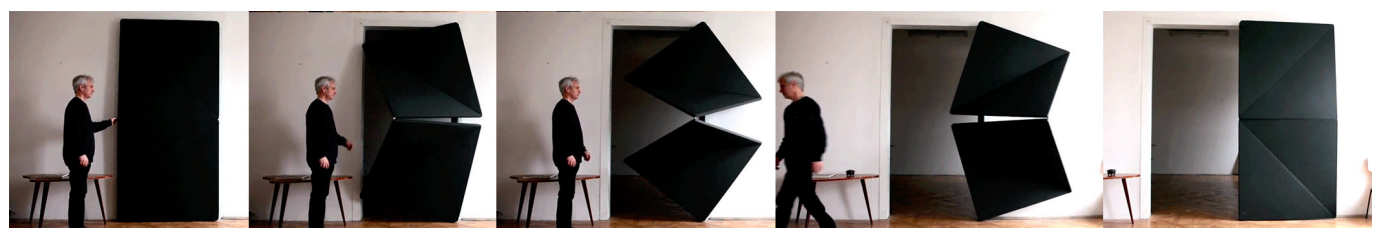

Fonte: Torggler (2015).

Além do contato com as propriedades do material em questão, a prática do origami possibilita o constante exercício de transformação do plano bidimensional para o tridimensional. O projeto de Torggler, detentor do raciocínio das dobras contemporâneas, possui uma economia de manufatura, de diferentes materiais (pois não têm dobradiças ou maçanetas) e mesmo uma economia de espaço. Quando a Evolution Door se abre, ocupa um espaço muito menor do que as portas tradicionais. Estas últimas, por constituírem-se de apenas uma única superfície plana e rígida, preenchem um espaço de 180응 que não pode ser ocupado por mais nada. Ao incorporar a linguagem da dobra e suas possibilidades, o projeto de Torggler demonstra por si próprio a mensagem de mutação inata que os objetos podem adquirir quando pensados como origamis contemporâneos. Tal prática do design que considera a forma como uma mensagem muito mais ampla foi apontada pelo filósofo Vilém Flusser:

O design, como todas as expressões culturais, mostra que a matéria não aparece (é inaparente), a não ser que seja informada, e assim, uma vez informada, começa a se manifestar (a torna-se um fenômeno). A matéria no design, como qualquer outro aspecto cultural, é o modo como as formas aparecem. (FLUSSER, 2007, p. 28).

O minimalismo da Evolution Door, além de possuir uma importância paradigmática baseada na sustentabilidade, carrega a problematização do origami em produzir sem excessos, precisão técnica de projeto do qual Stewart questiona: "dado um diagrama de linhas dobráveis em um pedaço de papel, poderá este papel ser dobrado de uma forma plana sem fazer nenhuma marca a mais?" (STEWART, 2007, p. 419, tradução nossa).

\section{DISCUSSÃO}

Bonsiepe (2011, p. 13) defende uma necessária conexão do design com outras diferentes áreas do conhecimento: ?Não se pode mais restringir o conceito de projeto às disciplinas projetuais como ocorre na arquitetura, no design industrial e no design de comunicação visual, pois nas disciplinas cientificas também há projeto.? (BONSIEPE, 2011, p. 19). Dada a necessidade de 
conexão de áreas objetivando um maior alcance de inovação com novas técnicas e métodos projetuais, o principal ponto a se discutir são como os trabalhos práticos do origami podem influenciar o processo criativo em design. Como colocado e estudado na introdução e no capítulo 2, o origami possui uma gestão de modelagem que possui aplicações em diversos âmbitos, escalas e situações do design internacional. Boa parte dessa ascensão técnica e metodológica devese ao caráter naturalmente experimental e dinâmico que a prática do origami conduz ao designer. Trabalhos como os do professor Ron Resch (resgatados e documentados atualmente por Mitya Miller, Erik Demaine e Robert Lang), trazem à tona a prática do origami em comunhão com o design no âmbito experimental. Diz Resch, em seu documentário, que ?o design é um tipo de ciclo de experiências entre o artista e o ambiente, entre o designer e alguns problemas posteriores." (RESCH, ARMSTRONG, 1992, tradução nossa). Os diversos experimentos com dobras de Resch fizeram com que o artista obtivesse, ao longo do tempo, muita experiência de aplicação diversificada do origami, tornando-o uma referência constante de busca para soluções empresariais. Enquanto pesquisador de estruturas interativas em dobras, o amplo trabalho de Resch fez com que concretizasse uma série de patentes, entre elas, o painel sanduíche a pedido da multinacional The Royal Packaging Industries Van Leer (RESCH, 1983).

Se por um lado, Resch mostrou a importância das práticas, improvisos e insights do origami de forma experimental, outros cientistas mostram hoje que a elucidação de teorias precisas e claras do processo criativo também possui relevância dentro do design e inovação. Com a gestão paradigmática entre design e engenharia no âmbito internacional, hoje o origami evolui a tal maneira que já possui formulações práticas e teóricas como o design baseado do origami e o design adaptado do origami, criadas e discutidas por Francis et al. (2014) e Morgan et al. (2016). É através dessas formulações que o processo criativo do origami projetual se torna mais claro, técnico e preciso para os designers.

\section{CONSIDERAC̣ÕES FINAIS}

Foram apontados nessa pesquisa algumas das muitas pontes de conhecimento, projetos e tecnologias que o origami conceitual alcança atualmente. Ao longo dessa investigação, notou-se que os estudos em origami científico auxiliam na realização de estruturas e produtos muito mais flexíveis e adaptáveis, o que contribui amplamente para a miscigenação de projetos que se conectam à nossa realidade contemporânea.

$\mathrm{Na}$ área do ensino, com a realização dos estudos dos professores Albers e Resch e, mais à frente, com diversos pesquisadores como Demaine e Lang, o origami ganhou potencial de prática projetual, proporcionando a busca do conhecimento e exploração dos materiais, estruturas e suas plasticidades. Além do exercício prático e experimental com os origamis, alguns exemplos aplicados foram mencionados e discutidos para entender melhor a ação projetual do origami de forma mais direta. Com o Origami Heart Stent, o 
origami alcançou a área da medicina na busca de maior conforto, segurança e exatidão de algumas cirurgias humanas. Com o programa Ori-Revo, o origami adquiriu status de construção digital e manual, abrindo novas possibilidades de mapeamento de projetos de produtos. Com a Evolution Door, o origami intermediou um paradigma minimalista e sustentável em um produto comum e do dia-a-dia. Esse artigo buscou contribuir para o aumento dos conhecimentos nacionais sobre o origami contemporâneo e sobre a natureza do pensamento e exploração das dobras.

\section{REFERÊNCIAS}

ANDREAS, B. Origami art as a means of facilitating learning. Procedia: Social and Behavioral Sciences, Sinaia, v. 11, p. 32-36, 2011. Disponível em: <http://www.sciencedirect.com/science/article/pii/ S1877042811000309>. Acesso em: 11 abr. 2016.

BONSIEPE, G. Design, cultura e sociedade. São Paulo: Blucher, 2011.

DELEUZE, G. A dobra: Leibniz e o barroco. Tradução de Luiz B. T. Orlandi. Campinas: Papirus, 1991.

DEMAINE, E. D. et al. A review on curved creases in art, design and mathematics. Symmetry: Culture and Science, Hungria, v. 26, n. 2, p. 145-161, July 2015.

DEMAINE, E. D. et al. Programmable matter by folding. Proceedings of The National Academy of Sciences of the United States of America, Washington, v. 107, n. 28, p. 12441-12445, July 2010.

FLUSSER, V. O mundo codificado: por uma filosofia do design e da comunicação. Tradução de Raquel Abi-Sâmara. São Paulo: Cosac Naify, 2007.

FRANCIS, K. C. et al. From crease pattern to product: considerations to engineering origami-adapted designs. In: INTERNATIONAL DESIGN ENGINEERING TECHNICAL, CONFERENCES AND COMPUTERS AND INFORMATION IN ENGINEERING CONFERENCE, 2014, Buffalo. Proceedings ... Buffalo: The American Society of Mechanical Engineers, 2014. p. 1-15. Disponível em: <http://proceedings.asmedigitalcollection. asme.org/ proceedingbrowse.aspx\#Year>. Acesso em: 11 abr. 2016.

FREDERICKSON, G. N. Hinged dissections: swinging \& twisting. Cambridge: Cambridge University Press, 2002.

HYDE, R. et al. Eyeglass: a very large aperture diffractive space telescope. In: SPIE HIGHLY INNOVATIVE SPACE TELESCOPE 
CONCEPTS, 2002, Washington. Proceedings ... Washington: SPIE The International Society for Optics and Photonics, 2002. p. 28-39.

KOMIYAMA, M. et al. Nanomechanical DNA origami 'single-molecule beacons' directly imaged by atomic force microscopy. Nature, Londres, v. 2, n. 44, p. 1-8, 2011. Disponível em: <http://www.nature.com/ ncomms/journal/v2/n8/full/ ncomms1452.html>. Acesso em: 11 abr. 2016.

KURIBAYASHI, K.; YOU, Z. A novel origami stent. In: SUMMER BIOENGINEERING CONFERENCE, 2003, Florida. Anais... Florida: Tulane University, 2003. Disponível em: <http://www.tulane.edu/ sbc2003/ pdfdocs/0257.PDF>. Acesso em: 25 maio 2015.

KURIBAYASHI, K.; YOU, Z. Expandable tubes with negative poisson's ratio and their application in medicine. In: ORIGAMI, INTERNATIONAL MEETING OF ORIGAMI SCIENCE, MATHEMATICS, AND EDUCATION, 4., 2006, Massachusetts. Proceedings ... Massachusetts: A K Peters, 2009.

LANG, R. J. Origami 4: fourth international meeting of origami science, mathematics, and education. Massachusetts: A K Peters, 2009.

LANG, R. J. Origami design secrets: mathematical methods for an ancient art. 2. ed. Massachusetts: A K Peters, 2003.

LANG, R. J.; IVERSON, P. W.; YIM, M. Origami 5: fifth international meeting of origami science, mathematics, and education.

Massachusetts: A K Peters, 2011.

MENGES, A. Fusing the computational and the physical: towards a novel material culture. Architectural Design, São Francisco, v. 85, n. 5, p. 8-15, 2015. Disponível em: <http://onlinelibrary.wiley.com/doi/10.1002/ ad.2015.85.issue-5/issuetoc>. Acesso em: 11 nov. 2015.

MITANI, J. A design method for 3D origami based on rotational sweep. Computer-Aided Design and Applications, Bangkok, v. 6, n. 1, p. 69-79, 2009. Disponível em: <http://mitani.cs.tsukuba.ac.jp/dl/ CAD_2009_3d_origami_based_on_rotational_sweep_mitani.pdf $>$. Acesso em: 31 maio 2015.

MORGAN, M. R. et al. Towards developing product applications of thick origami using the offset panel technique. Mechanical Sciences, Elmsford, v. 7, n. 1, p. 69-77, mar. 2016. Disponível em: <http://www. mech-sci.net/7/69/2016/ms-7-69-2016.html>. Acesso em: 2 abr. 2016.

RESCH Ron; ARMSTRONG, Elmer. The Ron Resch paper and stick film. 
Direção de Ronald D. Resch. Salt Lake City, UT : Resch Films, (c)1992. Vídeo em VHS. sound, color ; 1/2 in. Disponível em: <https://vimeo. com/36122966>. Acesso em: 28 jun. 2016.

RESCH, R. D. Construction-element. US4397902 A, 27 dez. 1977, 9 ago. 1983. Disponível em: <https://www.google.com/patents/US4397902>. Acesso em: 28 jun. 2016.

RON RESH OFFICIAL WEBSITE. The Works of Ron Resch. 2016. Disponível em: <http://www.ronresch.org/ronresch/>. Acesso em: 28 jun. 2016.

ROTHEMUND, P. W. K. Folding DNA to create nanoscale shapes and patterns. Nature, Londres, v. 440, n. 7082, p. 297-302, 2006. Disponível em: <http://www.nature.com/nature/journal/v440/n7082/ full/nature04586.html>. Acesso em: 11 abr. 2016.

STEWART, I. Some assembly needed. Nature, Londres, v. 448, p. 419419, jul. 2007.

TORGGLER, K. The evolution door. Viena: [s.n.], 2015. Disponível em: <http://www.torggler.co.at/>. Acesso em: 11 nov. 2015.

WEB OF SCIENCE. Base de dados online. Thomson Reuters, 2016. Disponível em: <http://apps.webofknowledge. com/CitationReport.do?product=UA\&search_ mode=CitationReport\&SID=3Dq7oUiuM3QZLe88YcE\&page $=1 \& \mathrm{cr}$ pqid=1\&viewType=summary $>$. Acesso em: 1 fev. 2016. 